\title{
An application: the Small Open Economy
}

\author{
Filipe Campante, Federico Sturzenegger \\ and Andrés Velasco
}

\section{Chapter 4 from}

\begin{tabular}{|c|c|}
\hline LSE Press & $\begin{array}{l}\text { Filipe Campante, } \\
\text { Federico Sturzenegger } \\
\text { and Andrés Velasco }\end{array}$ \\
\hline $\begin{array}{l}\text { ADVANCED MACRO- } \\
\text { ECONOMICS } \\
\text { aneasy gave }\end{array}$ & $\begin{array}{c}\text { Advanced Macro- } \\
\text { economics }\end{array}$ \\
\hline 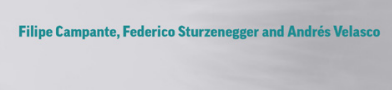 & SE Press \\
\hline
\end{tabular}

Suggested citation: Campante, Filipe; Sturzenegger, Federico; and Velasco, Andrés. (2021) 'An application: the Small Open Economy', in Filipe Campante, Federico Sturzenegger and Andrés Velasco, Advanced Macro-Economics: An Easy Guide. London: LSE Press, 2021. Chapter 4. https://doi.org/10.31389//sepress.ame.d under a Creative Commons Attribution NonCommercial licence allowing users to distribute, remix, adapt, and build upon the material in any medium or format, so long as attribution is given to the creator. The license does not allow for commercial use. 


\section{An application: The small open economy}

The Neoclassical Growth Model (NGM) is more than just a growth model. It provides us with a powerful tool to think about a number of questions in macroeconomics, which require us to think dynamically. So let's now put it to work!

We will do so in a simple but important application: understanding the capital accumulation dynamics for a small open economy. As we will see shortly, in an open economy the capital accumulation process is modified by the possibility of using foreign savings. This really allows countries to move much faster in the process of capital accumulation (if in doubt ask the Norwegians!), and is one of the main reasons why integrating into world capital markets is often seen as a big positive for any economy.

The use of foreign savings (or the accumulation of assets abroad) is summarised in the economy's current account, so the NGM applied to a small open economy can be thought of as yielding a model of the behaviour of the current account. The current account provides a measure of how fast the country is building foreign assets (or foreign debt), and as such it is a key piece to assess the sustainability of macroeconomic policies. We will also see that the adjustment of the current account to different shocks can lead to surprising and unexpected results. Finally, the framework can be used to analyse, for example, the role of stabilisation funds in small open economies.

\section{1 $\quad$ Some basic macroeconomic identities}

A quick refresher that introduces the concept of the current account.

A good starting point is to start with the basic macroeconomic identities, which you have seen before in your introductory and intermediate macro courses. Recall the relationship between GNP (Gross National Product, the amount that is paid to a country's residents) and GDP (Gross Domestic Product, the amount of final goods produced in a particular country):

$$
G D P+r B=G N P,
$$

\section{How to cite this book chapter:}

Campante, F., Sturzenegger, F. and Velasco, A. 2021. Advanced Macroeconomics: An Easy Guide.

Ch. 4. 'An application: The small open economy', pp. 41-50. London: LSE Press.

DOI: https://doi.org/10.31389/lsepress.ame.d License: CC-BY-NC 4.0. 
where $B$ is the position held by residents in foreign assets (net of domestic assets held by foreigners), and $r$ is the rate of return paid on those assets. In other words, $r B$ is the total (net) interest payments made by foreigners to residents. Notice that countries with foreign assets will have a GNP which is larger than GDP, whereas countries with debt will have a GNP which is smaller than their GDP.

Starting from the output equation we have that

$$
G N P=C+I+G+X-M+r B
$$

where $C, I, G, X$ and $M$, stand, as usual, for consumption, investment, government expenditures, exports and imports. This can be rewritten as:

$$
\begin{gathered}
\underbrace{G N P-C-G}_{S-I=X-M+r B=C A .}-I=X-M+r B=C A,
\end{gathered}
$$

The right-hand side (RHS) is roughly the current account $C A$ (the trade balance plus the net income on net foreign assets, which is typically called primary income, add up to the current account). ${ }^{1}$ The equation says that the current account is equal to the difference between what the economy saves $(S)$ and what it invests $(I) .^{2}$

Another alternative is to write this as:

$$
\begin{gathered}
G N P-\underbrace{C-G-I}_{Y-A b s o r p t i o n}=X-M+r b=C A, \\
Y-M+r b=C A,
\end{gathered}
$$

which clearly shows that a current account is the difference between income and absorption. In common parlance: if a country spends more than it earns, it runs a current account deficit. Importantly, and as we will see over and over again, this does not mean that current account deficits are bad! They simply mean that a country is using debt and, as always, whether that is a good or a bad thing hinges on whether that is done in a sustainable way. To figure that out, we need to embed these accounting identities into an optimising intertemporal model of how consumption and investment are chosen given current and future output.

As luck would have it, this is exactly what the NGM is!

\subsection{The Ramsey problem for a small open economy}

We will solve the (benevolent central planner) Ramsey problem for a small open economy. The key conclusions are: (i) $c=c^{*}$ : consumption can be perfectly smoothed; (ii) $f^{\prime}\left(k^{*}\right)=r$ : the capital stock can adjust immediately via foreign borrowing, and thus becomes independent of domestic savings. This is because the current account allows the economy to adjust to shocks while maintaining optimal levels of consumption and capital stock.

Here is where we will start using, right away, what we learnt in the previous chapter. As before, there is one infinitely-lived representative household whose members consume and produce. Population growth is now assumed to be $n=0$ for simplicity; initial population $L_{0}$ is normalised to 1 , so that all quantities are in per capita terms (in small-case letters). There is one good, and no government.

The key difference is that now the economy is open, in the sense that foreigners can buy domestic output, and domestic residents can buy foreign output. Whenever domestic income exceeds domestic 
expenditure, locals accumulate claims on the rest of the world, and vice versa. These claims take the form of an internationally-traded bond, denominated in units of the only good. The economy is also small, in the sense that it does not affect world prices (namely the interest rate), and thus takes them as given.

We will assume also that the country faces a constant interest rate. The constancy of $r$ is a key defining feature of the small country model. However, this is a strong assumption - if a country borrows a lot, probably its country risk would increase and so would the interest rate it would have to pay - but we will keep this assumption for now. (We will return to issues of risk when we talk about consumption and investment, in (Chapters 13 and 14.)

The utility function is exactly as before (with $n=0$ ):

$$
\int_{0}^{\infty} u\left(c_{t}\right) e^{-\rho t} d t
$$

The resource constraint of the economy is

$$
\dot{k}_{t}+\dot{b}_{t}=f\left(k_{t}\right)+r b_{t}-c_{t} .
$$

The novelty is that now domestic residents own a stock $b_{t}$ of the bond, whose rate of return is $r$, which is a constant from the standpoint of the small open economy. What is the current account in this representation? It is income (GNP), which is $f\left(k_{t}\right)+r b_{t}$, minus consumption $c_{t}$, minus investment $\dot{k}_{t}$. In other words, it is equal to $\dot{b}_{t}$. A current-account surplus is equivalent to an increase in foreign bond holdings.

In the open economy, we also have to impose a no-Ponzi game (NPG) condition (or solvency condition):

$$
\lim _{T \rightarrow \infty}\left(B_{T} e^{-r T}\right)=\lim _{T \rightarrow \infty}\left(b_{T} e^{-r T}\right) \geq 0 .
$$

This condition - again, not to be confused with the transversality condition (TVC) we met in the previous chapter - did not apply to the benevolent central planner (BCP) in the last chapter because they could not borrow in the context of a closed economy. It did apply to the consumers in the decentralised equilibrium though, and here it must apply to the economy as a whole. It means that the economy cannot run a Ponzi scheme with the rest of the world by borrowing money indefinitely to pay interest on its outstanding debt. In other words, this rules out explosive trajectories of debt accumulation under the assumption that foreigners would eventually stop lending money to this pyramid scheme.

\subsubsection{A useful transformation}

Define total domestic assets per capita as

$$
a_{t}=k_{t}+b_{t} \text {. }
$$

Then, (4.6) becomes

$$
\dot{a}_{t}=r a_{t}+f\left(k_{t}\right)-r k_{t}-c_{t},
$$

and (4.7) becomes

$$
\lim _{T \rightarrow \infty}\left[\left(a_{T}-k_{T}\right) e^{-r T}\right] \geq 0 .
$$




\subsubsection{Solution to consumer's problem}

The consumer maximises (4.5) subject to (4.9) and (4.10) for given $k_{0}$ and $b_{0}$. The Hamiltonian for the problem can be written as

$$
H=u\left(c_{t}\right)+\lambda_{t}\left[r a_{t}+f\left(k_{t}\right)-r k_{t}-c_{t}\right] .
$$

Note $c$ is one control variable (jumpy), and $k$ now is another control variable (also jumpy). It is now $a$ that is the state variable (sticky), the one that has to follow the equation of motion. $\lambda$ is the costate variable (the multiplier associated with the intertemporal budget constraint, also jumpy). The costate has the same intuitive interpretation as before: the marginal value as of time $t$ of an additional unit of the state (assets $a$, in this case). (Here is a question for you to think about: why is capital a jumpy variable now, while it used to be sticky in the closed economy?)

The first order conditions are then:

$$
\begin{gathered}
u^{\prime}\left(c_{t}\right)=\lambda_{t}, \\
f^{\prime}\left(k_{t}\right)=r, \\
\dot{\lambda}=-r \lambda_{t}+\rho \lambda_{t},
\end{gathered}
$$

and

$$
\lim _{t \rightarrow \infty} a_{t} \lambda_{t} e^{-\rho t}=0
$$

Using (4.12) in (4.14), we obtain

$$
u^{\prime \prime}\left(c_{t}\right) \dot{c}_{t}=(-r+\rho) u^{\prime}\left(c_{t}\right)
$$

Dividing both sides by $u^{\prime}\left(c_{t}\right)$ and using the definition of the elasticity of intertemporal substitution, $\sigma$, gets us to our Euler equation for the dynamic behaviour of consumption:

$$
\frac{\dot{c}_{t}}{c_{t}}=\sigma(r-\rho)
$$

This equation says that per-capita consumption is constant only if $r=\rho$, which we assume from now on. Notice that we can do this because $r$ and $\rho$ are exogenous. This assumption eliminates any inessential dynamics (including endogenous growth) and ensures a well-behaved BGP. ${ }^{3}$ It follows then that consumption is constant:

$$
c_{t}=c^{*}
$$

\subsubsection{Solving for the stock of domestic capital}

FOC (4.13) says that the marginal product of (per-capita) capital is constant and equal to the interest rate on bonds. Intuitively, the marginal return on both assets is equalised. This means that capital is always at its steady state level $k^{*}$, which is defined by

$$
f^{\prime}\left(k^{*}\right)=r .
$$


This means, in turn, that domestic per capita income is constant, and given by

$$
y^{*}=f\left(k^{*}\right) .
$$

Note that the capital stock is completely independent of savings and consumption decisions, which is a crucial result of the small open economy model. One should invest in capital according to its rate of return (which is benchmarked by the return on bonds), and raise the necessary resources not out of savings, but out of debt.

\subsubsection{The steady state consumption and current account}

Now that you have the level of income you should be able to compute the level of consumption. How do we do that? By solving the differential equation that is the budget constraint (4.9), which we can rewrite as

$$
\dot{a}_{t}-r a_{t}=f\left(k^{*}\right)-r k^{*}-c^{*},
$$

using the solutions for optimal consumption and capital stock. Using our strategy of integrating factors, we can multiply both sides by $e^{-r t}$, and integrate the resulting equation between 0 and $t$ :

$$
a_{t} e^{-r t}-a_{0}=\frac{c^{*}+r k^{*}-f\left(k^{*}\right)}{r}\left(e^{-r t}-1\right) \text {. }
$$

Now evaluate this equation as $t \rightarrow \infty$. Considering the NPC and the TVC, it follows that:

$$
c^{*}=r a_{0}+f\left(k^{*}\right)-r k^{*} .
$$

We can also find the optimal level of debt at each time period. It is easy to see that $a_{t}$ is kept constant at $a_{0}$, from which it follows that $b_{t}=b_{0}+k_{0}-k^{*}$. The current account is zero. In other words, the NGM delivers a growth model with no growth, as we saw in the last chapter, and a model of the current account dynamics without current account surpluses or deficits.

Not so fast, though! We saw that the NGM did have predictions for growth outside of the BGP. Let's look at the transitional dynamics here as well, and see what we can learn.

\subsubsection{The inexistence of transitional dynamics}

There are no transitional dynamics in this model: output per capita converges instantaneously to that of the rest of the world!

Suppose that initial conditions are $k_{0}<k^{*}$ and $b_{0}>0$. But, condition (4.19) says that capital must always be equal to $k^{*}$. Hence, in the first instant, capital must jump up from $k_{0}$ to $k^{*}$. How is this accomplished? Domestic residents purchase the necessary quantity of capital (the single good) abroad and instantaneously install it. Put differently, the speed of adjustment is infinite.

How do the domestic residents pay for this new capital? By drawing down their holdings of the bond. If $\Delta k_{0}=k^{*}-k_{0}$, then $\Delta b_{0}=-\Delta k_{0}=-\left(k^{*}-k_{0}\right)$. Note that this transaction does not affect initial net national assets, since

$$
\Delta a_{0}=\Delta k_{0}+\Delta b_{0}=\Delta k_{0}-\Delta k_{0}=0
$$




\section{An example}

Suppose now that the production function is given by

$$
f\left(k_{t}\right)=A k_{t}^{\alpha}, A>0,0 \leq \alpha \leq 1 .
$$

This means that condition (4.19) is

$$
\alpha A\left(k^{*}\right)^{\alpha-1}=r
$$

so that the level of capital on the BGP is

$$
k^{*}=\left(\frac{\alpha A}{r}\right)^{\frac{1}{1-\alpha}},
$$

which is increasing in $A$ and decreasing in $r$.

Using this solution for the capital stock we can write $y^{*}$ as

$$
y^{*}=A k^{* \alpha}=A\left(\frac{\alpha A}{r}\right)^{\frac{\alpha}{1-\alpha}}=A^{\frac{1}{1-\alpha}}\left(\frac{\alpha}{r}\right)^{\frac{\alpha}{1-\alpha}} \equiv z(A),
$$

with $z(A)$ increasing in $A$.

It follows that consumption can be written as

$$
c^{*}=r a_{0}-r k^{*}+z(A)=r a_{0}+(1-\alpha) z(A),
$$

with $z^{\prime}(A)>0$.

\subsection{6 | Productivity shocks and the current account}

Suppose the economy initially has total factor productivity $A^{H}$, with corresponding optimal stock of capital $\left(k^{*}\right)^{H}$ and consumption level $\left(c^{*}\right)^{H}$. At time 0 there is an unanticipated and permanent fall in productivity from $A^{H}$ to $A^{L}$, where $A^{L}<A^{H}$ (maybe because this economy produced oil, guano, or diamonds and its price has come down). This means, from (4.28), that $z(A)$ falls from $z\left(A^{H}\right)$ to $z\left(A^{L}\right)$. Capital holdings are reduced: residents sell capital in exchange for bonds, so after the shock they have $\left(k^{*}\right)^{L}<\left(k^{*}\right)^{H}$, where $\left(k^{*}\right)^{H}$ was the optimal stock of capital before the shock. Assets $a_{0}$ are unchanged on impact.

From (4.29) it follows that consumption adjusts instantaneously to its new (and lower) value:

$$
\left(c^{*}\right)^{L}=r a_{0}-(1-\alpha) z\left(A^{L}\right)<r a_{0}-(1-\alpha) z\left(A^{H}\right)=\left(c^{*}\right)^{H}, \text { for all } t \geq 0 .
$$

What happens to the current account? After the instantaneous shock, assets remain unchanged, and $\dot{b}_{t}$ is zero. The economy immediately converges to the new BGP, where the current account is in balance.

At this point, you must be really disappointed: don't we ever get any interesting current account dynamics from this model? Actually, we do! Consider a transitory fall in productivity at time 0 , from $A^{H}$ to $A^{L}$, with productivity eventually returning to $A^{H}$ after some time $T$. Well, it should be clear that consumption will fall, but not as much as in the permanent case. You want to smooth consumption, and you understand that things will get back to normal in the future, so you don't have to bring it down so much now. At the same time, the capital stock does adjust down fully, otherwise its return would be below what the domestic household could get from bonds. If current output falls just as in the permanent case, but consumption falls by less, where is the difference? A simple inspection of (4.9) 
reveals that $\dot{b}$ has to fall below zero: it's a current-account deficit! Quite simply, residents can smooth consumption, in spite of the negative shock, by borrowing resources from abroad. Once the shock reverts, the current account returns to zero, while consumption remains unchanged. In the new BGP, consumption will remain lower relative to its initial level, and the difference will pay for the interest incurred on the debt accumulated over the duration of the shock - or more generally, the reduction in net foreign asset income.

This example underscores the role of the current account as a mechanism through which an economy can adjust to shocks. It also highlights one feature that we will see over and over again: the optimal response and resulting dynamics can be very different depending on whether a shock is permanent or transitory.

\subsection{7 | Sovereign wealth funds}

This stylised model actually allows us to think of other simple policy responses. Imagine a country that has a finite stock of resources, like copper. ${ }^{4}$ Furthermore let's imagine that this stock of copper is being extracted in a way that it will disappear in a finite amount of time. The optimal program is to consume the net present value of the copper over the infinite future. So, as the stock of copper declines the economy should use those resources to accumulate other assets. This is the fiscal surplus rule implemented by Chile to compensate for the depletion of their resources. In fact, Chile also has a rule to identify transitory from permanent shocks, with the implication that all transitory increases (decreases) in the price level have to be saved (spent).

Does this provide a rationale for some other sovereign wealth funds? The discussion above suggests that a country should consume:

$$
r \int_{-\infty}^{\infty} R_{t} e^{-r t} d t
$$

where $R$ is the value of the resources extracted in period $t$. This equation says that a country should value its intertemporal resources (which are the equivalent of the $a_{0}$ above, an initial stock of assets), and consume the real return on it.

Is that how actual sovereign funds work? Well, the Norwegian sovereign fund rule, for instance, does not do this. Their rule is to spend at time $t$ the real return of the assets accumulated until then:

$$
r \int_{-\infty}^{t} R_{t} e^{-r(s-t)} d s
$$

This rule can only be rationalised if you expect no further discoveries and treat each new discovery as a surprise. Alternatively, one could assume that the future is very uncertain, so one does not want to commit debt ahead of time. (We will come back to this precautionary savings idea in our study of consumption in Chapter 11.) In any event, the key lesson is that studying our stylised models can help clarify the logic of existing policies, and where and why they depart from our basic assumptions.

\subsection{What have we learned?}

The NGM provides the starting point for a lot of dynamic macroeconomic analysis, which is why it is one of the workhorse models of modern macroeconomics. In this chapter, we have seen how it provides us, in the context of a small open economy, with a theory of the current account. When 
an economy has access to international capital markets, it can use them to adjust to shocks, while smoothing consumption and maintaining the optimal capital stock. Put simply, by borrowing and lending (as reflected by the current account), the domestic economy need not rely on its own savings in order to make adjustments.

This brings to the forefront a couple of important messages. First, current account deficits (contrary to much popular perception) are not inherently bad. They simply mean that the economy is making use of resources in excess of its existing production capacity. That can make a lot of sense, if the economy has accumulated assets or otherwise expects to be more productive in the future.

Second, access to capital markets can be a very positive force. It allows economies to adjust to shocks, thereby reducing volatility in consumption. It is important to note that this conclusion is coming from a model without risk or uncertainty, without frictions in capital markets, and where decisions are being taken optimally by a benevolent central planner. We will lift some of those assumptions later in the book, but, while we will not spend much more time talking about open economies, it is important to keep in mind those caveats here as well.

Third, we have seen how the adjustment to permanent versus transitory shocks can be very different. We will return to this theme over and over again over the course of this book.

Last but not least, we have illustrated how our stylised models can nevertheless illuminate actual policy discussions. This will, again, be a recurrent theme in this book.

\subsection{What next?}

The analysis of the current account has a long pedigree in economics. As the counterpart of current accounts are either capital flows or changes in Central Bank reserves it has been the subject of much controversy. Should capital accounts be liberalised? Is there a sequence of liberalisation? Can frictions in capital markets or incentive distortions make these markets not operate as smoothly and beneficially as we have portrayed here? The literature on moral hazard, the policy discussion on bailouts, and, as a result, all the discussion on sovereign debt, which is one key mechanism countries, smooth consumption over time. The presentation here follows Blanchard and Fischer (1989), but if you want to start easy you can check the textbook by Caves et al. (2007), which covers all the policy issues. Obstfeld and Rogoff (1996) is the canonical textbook in international finance. More recently, you can dwell in these discussions by checking out Vegh (2013) and Uribe and Schmitt-Grohé (2017). Last, but not least, the celebrated paper by Aguiar and Gopinath (2007) distinguishes between shocks to output and shocks to trends in output growth, showing that the latter are relevant empirically and help understand the current account dynamics in emerging economies.

\section{Notes}

${ }^{1}$ We should add secondary income, but we will disregard for the analysis.

2 The fact that current accounts seem to be typically quite small relative to the size of the economy, so that savings is roughly similar to investment, is called the Feldstein-Horioka puzzle.

${ }^{3}$ Think about what happens, for instance, if $r>\rho$. We would have consumption increasing at a constant rate. This patient economy, with relatively low $\rho$, would start accumulating assets indefinitely. But in this case, should we expect that the assumption that it is a small economy would keep being appropriate? What if $r<\rho$ ? This impatient economy would borrow heavily to enjoy a high level of 
consumption early on, and consumption would asymptotically approach zero as all income would be devoted to debt payments - not a very interesting case.

${ }^{4}$ Is this example mere coincidence, or related to the fact that one of us is from Chile, which is a major exporter of copper? We will let you guess.

\section{References}

Aguiar, M. \& Gopinath, G. (2007). Emerging market business cycles: The cycle is the trend. Journal of Political Economy, 115(1), 69-102.

Blanchard, O. \& Fischer, S. (1989). Lectures on macroeconomics. MIT Press.

Caves, R. E., Frankel, J., \& Jones, R. (2007). World trade and payments: An introduction. Pearson.

Obstfeld, M. \& Rogoff, K. (1996). Foundations of international macroeconomics. MIT Press.

Uribe, M. \& Schmitt-Grohé, S. (2017). Open economy macroeconomics. Princeton University Press.

Vegh, C. (2013). Open economy macroeconomics in developing countries. MIT Press. 